\title{
The Place of Grammar Instruction in the 21st Century: Exploring Global Perspectives of English Teachers towards the Role of Teaching Grammar in EFL/ESL Classrooms
}

\author{
Mohammad H. Al-khresheh ${ }^{1} \&$ Suheyla Demirkol Orak ${ }^{2}$ \\ ${ }^{1}$ Department of English Language, Faculty of Science and Arts, Northern Border University, Saudi Arabia \\ ${ }^{2}$ School of Foreign Languages, Firat University, Turkey \\ Correspondence: Mohammad H. Al-khresheh, Department of English Language, Faculty of Science and Arts, \\ Northern Border University, Saudi Arabia.
}

Received: December 29, 2020

Accepted: March 1, $2021 \quad$ Online Published: March 10, 2021

doi:10.5430/wjel.v11n1p9

URL: https://doi.org/10.5430/wjel.v11n1p9

\begin{abstract}
This study explores the perspectives held by English teachers around the world regarding the role of teaching grammar in EFL/ESL classrooms and whether the divergence in these perspectives is influenced by variables such as gender, country, seniority, or educational background of the participants. To accomplish these objectives, a comprehensive questionnaire survey from literature comprising 46 items was carried out on a group of 304 participants from 22 countries who were voluntarily involved in this study using the snowball sampling method. Descriptive statistical methods were deployed for accurate data analysis. The findings revealed that the participants had a positive and constructive attitude regarding the importance of grammar instruction and were in unanimous agreement that good grammatical skills enabled the faster acquisition of proficiency in the target language. The participants agreed that grammatical mistakes' immediate correction was detrimental students' self-confidence levels and considered unnecessary interruption. These views highly influenced teaching methods and classroom practices. An overwhelming majority preferred an inductive and explicit approach to grammar teaching. It was concluded that while statistical differences in age, gender, and educational background did not influence the participants' perspectives, seniority and country of origin played a vital role in these beliefs. After due consideration of these findings, a comprehensive discussion of the pedagogical implications and recommendations has been presented in this study.
\end{abstract}

Keywords: English, EFL/ESL teachers, grammar, perceptions, teaching methods

\section{Introduction}

Experts widely regard modern human languages to be rule-governed or conventional methods of communication. As a matter of fact, the term 'communication' implies the existence of a defined set of standards, rules, and regulations that have to be observed while sharing information, which allows the meaning of common words to remain consistent across different people and places (Burchfield, 2006; McWhorter, 2012). Mair (2005) provided a clear definition of the differences between certain instances of language behaviour and shared language, which were the basis of de Saussure's statements when he spoke about parole and language notions. Language can be considered a system of conventions, an abstraction, or a social set of rules, which is crucial for successful communications between members hailing from the same linguistic community (McGregor, 2009).

In today's world, English has ascended a global language and is the world's lingua franca. With over 350 million native speakers and 430 million speakers who learned it as their second language (L2), the ability to speak English can help speakers immensely in this era of globalization. It is the only language that is studied worldwide, one that almost every educated person uses for getting their views, communication, and opinions to others across different cultures (Eaton, 2010; Pandian et al., 2011). English has enabled people from all over the globe to communicate seamlessly with one another and is a rich source of knowledge in the current age of technology and science. Although English learning tends to begin at the kindergarten level in most countries around the world, it is disturbing to discover that many high school pupils are incapable of constructing coherent sentences in English. This makes us question the validity of the elementary education system they grew up in. Was not English taught adequately enough 
during grade school? (Hurn \& Tomalin, 2013; Iqbal et al., 2017; Rao, 2019).

The arduous struggle with grammar is among the greatest troubles plaguing English teachers and students alike. It is, after all, the foundation upon which a language is learnt. It forms the heart of the language and lends logic to speech. English language learners must be aware of rudimentary grammatical concepts inherent to the English language and learn to augment their communication skills effectively (Pudin, 2017). Unless they have imbibed English language's grammatical rules and concepts, the grammatical rules and concepts accurately, their ability to express thoughts and ideas with precision will remain severely limited. Since grammar has a fundamental role in language learning, it is undoubtedly one of the first things that learners must be taught. Failure to understand it could result in diminished communication abilities and catastrophic results in the long run (Alsied et al., 2018).

As Ellis (2006) pointed out, grammar remains a widely-debated controversial topic in the world of L2 teaching and applied linguistics. It is not helped by the fact that English is infamously difficult to learn due to its complex and archaic grammar rules. Mere ability to speak and write in the language does not make anyone an expert in teaching it. Becoming a skilled language teacher is an arduous task that demands years of rigorous training to acquire the appropriate skills (Fandino, 2013). Knowing how to speak the language cannot, and will not, instil these skills by default in English speakers (Yusof, 2018).

Although certain issues have been resolved now, owing to education bodies' efforts, teaching grammar efficiently is a skill that requires further research due to the numerous issues linked to it. Several leading research institutes have now recognised teaching to be a cognitive process that is largely dictated by the beliefs of the teachers. As a result, the attitudes and beliefs of teachers are now increasingly analysed for a better understanding of the theoretical concepts associated with teaching grammar, like the nature of explicit and implicit teaching, the role played by different evaluative feedback option, the best method to teach grammar, and the mammoth role that practice plays in language acquisition (Brown \& Rodgers, 2002; Canh \& Barnard, 2009; Onalan, 2018A)

There are several schools of thought on the best way to teach grammar to students. Based on the tenacity of researchers looking to better understand language teaching, studies are now challenging previously unshakeable assumptions regarding the effective methods. The English language teaching methods deployed in classrooms today are all rooted in extensive research studies of actual classroom behaviour. Since grammar is a highly-complex topic to deal with, teachers are inclined to deploy instructional practices that are better aligned with their beliefs and theories regarding language teaching and learning. It is a well-known fact that when language teachers come into their own after graduation, they combine their ideas, knowledge, and experience to form beliefs. New evidence suggests that teachers base their beliefs with regards to teaching upon concrete practical theories that have been shaped by numerous factors, both in the classroom and beyond it (Bernat \& Gvozdenko, 2005; Basturkmen, 2012).

Due to the vast power that beliefs exercise in the teachers' mind, their impact on language learning and teaching must be researched in detail since they could hold the key to overhauling, revamping, and upgrading the current English learning and teaching system. Numerous educational and research institutions have taken it upon themselves to understand the role of beliefs in influencing English language teachers' efficiency levels (Farrell \& Kun, 2007). The results of such studies have helped us understand the intricacies and cognitive framework that surrounds the instructional practices of language teachers. Consequently, this study seeks to answer two critical research questions, considering that the answers are taken from a global context.

[1] What perceptions do English teachers have towards the role of teaching grammar in EFL/ESL classrooms?

[2] Do English teachers' perceptions towards the role of teaching grammar in EFL/ESL classrooms diverge noticeably in terms of gender, country, seniority, background education, and age?

\section{Literature Review}

Teaching English grammar effectively can enable the linguistic development and advancement of language learners by organizing their language skills sustainably and structurally (Larsen-Freeman, 2001). When the adequate focus is placed on form and meaning, learners will become capable of acquiring language skills efficiently to accomplish their targeted learning outcomes. Language learning is affected to a great degree by one's grammar skills. Pagcaliwagan (2016) claimed that when English learners are given constant exposure to grammar, their ability to use them increases. Studies have shown that grammar skills are crucial for L2 language learners looking to augment their learning abilities. Previously, teachers have been using the grammar-translation method, which involves using the learner's native language to explain the meaning of terms in the target language. Nonetheless, experts researching L2 acquisition skills have been debating which grammar teaching method to use for the last 40 years. Language teachers themselves are in disagreement here. While some believe that the best way to teach grammar is by teaching it 
incidentally, which involves focusing on the form, others believe in teaching grammatical rules explicitly along with a strong focus on its form. This section reviews grammar definition, grammar instructions, and recent studies into the grammar teaching beliefs held by language teachers (Al-Mekhlafi \& Nagaratnam, 2011; Barnard \& Scampton, 2008; Richards \& Rodgers, 2016; Larsen-Freeman, 2001; Diaz et al., 2019).

\subsection{Grammar Definition}

Linguists and scholars have defined the term 'grammar' in different ways. Grammar is traditionally defined to mean the way words are utilized to form sentences. It helps one understand how different words work together to create complex sentences and speech (Morenberg, 1991). Grammar is considered the practice and study of the various rules that dictate how words modify their forms to be assembled into sentences. This definition has two fundamental elements: grammatical rules and an analysis of how these rules are to be studied and practised. It forms the fundamental framework of a language (Morenberg, 199; Önalan, 2018B; Lin, 2016; Ellis, 2006; Duddleston \& Pullum, 2003)

According to Morenberg (1991), language learners are taught to treat grammar as a guidebook encompassing the rules of using a language. It provides language rules needed by speakers to communicate effectively. In the Longman dictionary of contemporary English, Procter (1978) asserts that grammar refers to the rules of language that allow words to change their formation to form new sentences. Crystal (2003) reveals that grammar dictates rules that control the workings of an efficient communication system.

\subsection{Grammar Instruction}

Over the last few decades, grammar instruction theories have gone through numerous revisions due to the on-going and long-standing discourse regarding the role of grammar in an L2 classroom. This has given birth to contradicting principles, methods, and ideologies. Grammar instruction involves different methods or systematic grammar teaching methods that help learners acquire a decent level of competence in an L2 (Afshar \& Bagherieh, 2014). Grammar instruction enables learners to understand the correct and specific language properties (Ruin, 1996). In short, grammar instruction involves using instructional techniques for helping learners understand the application of different grammatical rules. However, the best methods to teach grammar may vary between different methodologists, researchers, and teachers. Although there are many approaches, at the moment, L2 teaching literature uses two grammar teaching approaches: inductive and deductive approaches.

As per Sharabyan (2011), both grammar learning and teaching are influenced to a great degree by these approaches. The deductive approach uses a teacher-centric model in which English grammatical rules are explicitly taught to students, followed by application. In this model, learners are taught general rules and then learn its application, followed by practice exercises to reinforce the concept. Grammatical lessons kick off with teachers presenting a particular rule that is then practised by students. Crystal (2003) states that the deductive grammar approach uses explicit, direct, and top-down methods to teach students grammatical structures. This approach allows teachers to provide logical reasons, explicit explanations, and accurate demonstrations of grammatical rules to their students. On the other hand, the inductive approach requires learners to detect and notice patterns independently to come up with 'rules' before practising the language. It is a discovery-focused learning system that revolves around the student and a bottom-up approach that allows grammatical structures to be inferred implicitly. The learning process uses various relevant communication contexts that are ripe with grammar patterns to be discovered. Learners formulate and generalize grammatical rules on their own via scaffolding - a process wherein they collaborate and cooperate to build knowledge structures and provide formative feedback to one another (Sato \& Oyanedel, 2019).

The differences between the above two approaches are incredibly straightforward. The former requires less time, but the latter has been proven to be far more effective in the long run. It should be noted that the results ultimately comes down to the efforts employed by students and teachers. The inductive approach might leave some students aggrieved, especially those that prefer a deductive and teacher-centric approach. Both these approaches need to be compared and evaluated by the teachers to determine which style works best for their classes (Due et al., 2015). To conclude, it could be noted that both inductive and deductive approaches come with their list of advantages and disadvantages. Several factors may affect the teacher's decision to go with either of them, including the language's overall nature and the learners and the teachers' overall preferences. Most experts recommend combining both approaches to generate the best results from an EFL classroom.

\subsection{Previous Studies on Grammar}

Due to the extraordinary power of beliefs, it is no surprise that they can influence human behaviour significantly. Beliefs play an enormous role in every discipline that deals with learning and human behaviour (Zheng, 2013; 
Tillema, 2000). Even in language teaching and learning, the beliefs held by teachers and learners affect the eventual outcome to such a tangible extent that several research studies have conducted an in-depth analysis of their influence. A teacher's core beliefs are reflected in teachers' instruction in their classroom (Li \& Walsh, 2011; Farrell \& Kun, 2007; Bell, 2016). Many studies have also explored the influence beliefs wield over grammar teaching instructions; this section is a review of the most insightful studies in this field. One of the most interesting studies was conducted by Burgess and Etherington (2002). Their study aimed to understand the beliefs and attitudes displayed by 48 British teachers regarding grammar instructions and grammar teaching in a de-contextualized design, unlike traditional discourse-based approaches. It was found that participants rated grammar to be a crucial factor for students to achieve successful communication skills in the language. Their experience also endowed them with a better understanding of vexing issues and problems teachers face in the classroom. The findings revealed that most teachers approved of a discourse-based approach instead of presenting grammatical rules without appropriate context to their students.

Another important study on a Singaporean primary school by Patricia (2003) revealed that the instructional practices were significantly influenced by numerous factors apart from their beliefs - some were even uncontrollable for all intents and purposes. Borg (2003) also reviewed over 64 language teacher cognition-focused studies - 38 of these studies analysed grammar teaching strategies. Most of these research studies were done in North America, Britain, and Europe, which gave rise to calls for the same research to be conducted in a diverse set of contexts for better accuracy.

Iqbal et al. (2017) found that most teachers at the secondary school level had almost limited English language specialization, thus leading to massive dissatisfaction levels with their English grammar teaching methods. The issue was only compounded by the fact that there were no programs to train secondary school English teachers. English teachers recommended using the audio-lingual method for better results. These teachers perceived English grammar to be a challenging topic to teach. In the same vein, Dorji (2018) discovered that Bhutanese teachers preferred teaching grammar via complete texts instead of teaching them in an isolated context. These results reveal that the Bhutanese consider a language's grammar to play an important role in a person's overall language acquisition abilities. Teachers were in agreement regarding the requirement for grammar rules to be explicitly taught. They believed that explaining the rules was particularly useful and attached a significant amount of importance to error corrections.

Due to the importance of this topic, more studies over the past three years were also conducted. For instance, Onalan (2018A) revealed that the teachers preferred teaching grammar directly by presenting grammar rules explicitly. They also reiterated that it was important to study grammar rules for effective usage of the target language. Experienced instructors were flexible in that they used a combination of indirect and direct grammar teaching methods. In contrast, novice teachers preferred direct and explicit grammar teaching and presentation of grammatical rules. Likewise, Yusof (2018) disclosed the challenges faced by English language teachers who taught at the undergraduate level. Over 15 university English teachers participated in his study, which revealed six primary challenges faced by them while teaching grammar - preparation of grammar lessons, negative perceptions regarding grammar teaching, lack of proper facilities, high expectations, and lack of ample experience. Besides, Diaz et al. (2019) found that Dominican language teachers widely adhered to traditional grammar teaching practices. The teachers' beliefs regarding grammar showed limited comprehension of the relationship between communicative fluency and grammatical accuracy, thus resulting in them adopting rule-based teaching strategies in increasing number. However, their study also revealed that teachers were engaged in an active discussion over the best teaching methods. Although many participants recognized grammar's importance in helping learners attain a certain proficiency level in the target language, it was not treated accordingly due to various factors.

The findings of Toprak (2019)'s study showed that most instructors were staunch believers about the importance of grammar in helping learners achieve a substantial level of proficiency in the English language. Additionally, teachers were also found to favour a communicative, integrative, and inductive approach towards grammar teaching.

To sum up, a thorough analysis of the literature provided here proves that a comprehensive understanding of the best grammar teaching practices cannot be achieved without an ethical analysis of what teachers themselves believe to be true about grammar. Their beliefs and practices merit a separate, comprehensive analysis of their own since the reasons backing those beliefs are just as much important. Instructors take teaching decisions that are in alignment with their theories about grammar. Teacher cognition, which involves focusing on understanding the way teachers know, believe, and think, is vital to understand their cognitive framework since it directly impacts the teaching choices and methods that they deploy. Therefore and due to the importance of teachers' beliefs in shaping their 
techniques and strategies in teaching grammar, this study was set frontward to explore more in-depth the perceptions of a group of intentional ESL/EFL teachers towards teaching grammar, taking into consideration their gender, country, seniority, background education, and age.

\section{Research Method}

A quantitative cross-section research design was carried out on 304 English language teachers hailing from 22 countries. From Asia to Europe, various ELT teachers were encouraged to participate regardless of their teaching level. Kumar (2011), stated 'cross-sectional (one-shot)' to be the best research design since it helped discover one's attitude, beliefs, or perceptions. Creswell (2002) and Li (2017) agreed that cross-sectional surveys, especially self-administered questionnaires, were an effective research design to study perceptions held by language teachers. Therefore, a self-administered questionnaire to aid data collection was used.

\subsection{Participants and Sampling}

To generalise the study's findings, the participants' data has been privileged. Over 304 participants from 22 countries, divided into 169 females and 135 males, with different levels of academic education (High School Degree, Associate Degree, Diploma Degree, Bachelor's Degree, Master's Degree and Doctorate Degree), and vast teaching experience (less than one year to more than 10 years), were involved in this study (more details about the characteristics of the study's participants are provided in the results and discussion section). A snowball sampling method was used with the help of mailed questionnaire forms to ensure a greater sample population. It was assumed that every contact would share this questionnaire with their contacts, thus increasing participant number akin to a snowball (See Figure1)

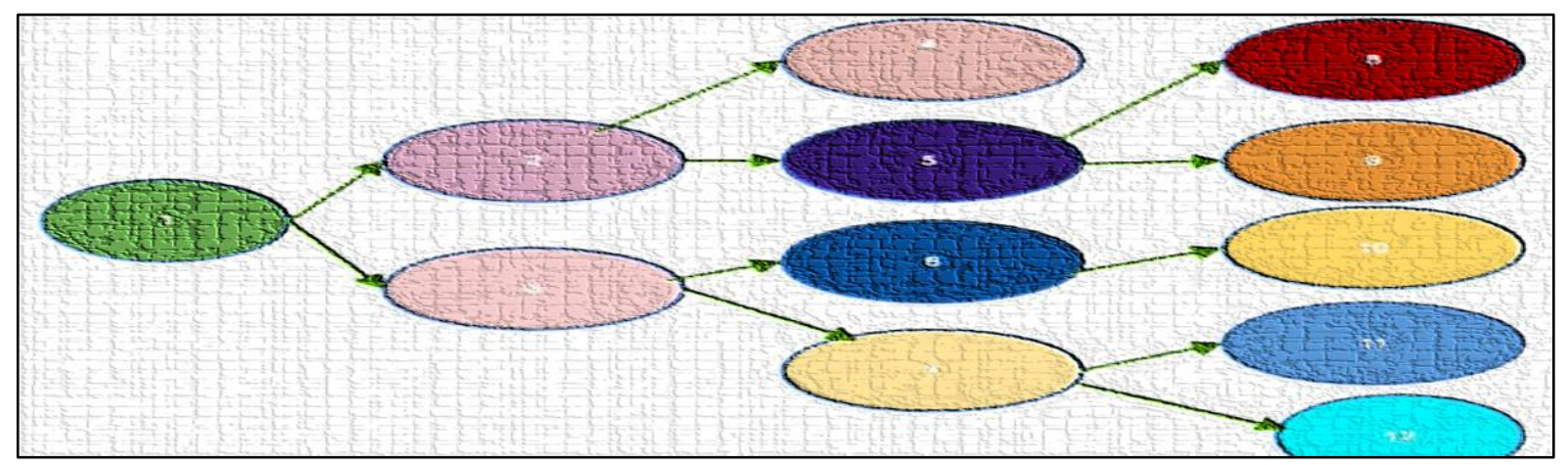

Figure 1. Snowball Sampling Model

\subsection{Data Collection Tool}

With a core aim of accurate data collection, a survey questionnaire developed by Barnard and Scampton (2008) was used in this study. This questionnaire was then revised to meet the objectives of the current study. Therefore, six items and five demographic questions that sought information regarding gender, country of origin, academic education, seniority, and age were also added to support the research questions. Finally, a 46 item Likert-scale type questionnaire with a four-factor modal was devised, with responses ranging from 'Strongly Agree' to 'Strongly Disagree', which was named 'The Questionnaire of Teachers' Perceptions regarding the Place of Grammar in ELT'. Before the questionnaire was administered, a piloting study was conducted, thus ensuring the questionnaire's reliability as it was prepared using items from different questionnaires presented in Table 1 below.

Table 1. Reliability Check of the Questionnaire

\begin{tabular}{lc} 
N of Items & 46 \\
$N$ of Participants & 50 \\
Cronbach's Alpha &, 838 \\
\hline
\end{tabular}

As presented in Table 1, Cronbach's alpha value, which stood at $0.838(\alpha>0.7)$, thus affirming the questionnaire's 
reliability. Based on this information, the mailed questionnaire form was administered to participants.

\subsection{Data Collection Process and Analysis}

As this was a one-shot study, it was decided to gather data from different contexts and cultures in high numbers. Questionnaires were sent via mails to prospective respondents since it was deemed the best data collection method for the purpose of this study (Kumar, 2011). Participants were duly informed regarding the overall scope of this study. Names were not involved at any stage for preserving anonymity. Collecting the responses took around one month. Reminder emails were regularly sent to participants as well.

When the saturation point was hit, the data was uploaded to SPSS v22 for analysis. Item 8 and Item 40 were negative, due to which they were reverse coded in both the piloting and the actual study. Descriptive statistics were utilised for responding to the first question. One-way ANOVA and independent samples t-test were utilised for the second research question and its sub-questions with independent and dependent variables. Variance homogeneity was tested accordingly before one-way ANOVA tests were employed. As it was a 4-factor model Likert-type questionnaire, a mean value of 3 or above was considered to be a positive indicator; a mean value between 2 and 3 was considered to be lukewarm to positive, and a mean value below 2 was considered a weak indicator of the ability of the items to gather information about the perceptions of teachers regarding grammar-oriented teaching methods.

\section{Results and Discussion}

The study's findings and relevant discussions have been presented in this section to accurately interpret the results, aided by relevant references and related output.

\subsection{What Perceptions Do English Teachers Have Towards the Role of Teaching Grammar in EFL/ESL Classrooms?}

Perceptions or beliefs may cause soldiers to fight and couples to marry. They may give rise to sicknesses and cures. Moreover, perceptions are considered by most leading experts to be a fundamental construct ubiquitous to all human disciplines (Brown \& Rodgers, 2002). Descriptive statistical methods were used for examining the perceptions of ELT teachers regarding the role of grammar, which has been presented in Table 2, which reveals that participants have a positive view towards adding ELT grammar instruction, with the cumulative mean value calculated at 103.53.

Table 2. Teachers' Perceptions of the Place of Grammar in ELT

\begin{tabular}{lc}
\hline Minimum & 64 \\
Maximum & 184 \\
Mean & 103.53 \\
Std. Deviation & 15.81 \\
Number of Participants & 304 \\
\hline
\end{tabular}

When these items were subject to analysis, the minimum mean value was found to be 1 . The maximum mean value was found to be 4 . The items' mean values ranged between $2.29-3.08$. There were no major gaps between the items' mean values. Item 40 'My learners cannot find the relations between forms and functions in real-life materials without teachers' clear explanation.' $(\mathrm{M}=2.29, \mathrm{SD}=.828)$, Item 42 'Teachers find it difficult to introduce suitable tasks on the basis of real-life materials.' $(\mathrm{M}=2.29, \mathrm{SD}=.817)$, and Item 45 'Teachers find it difficult to correct learners' mistakes in communicative writing' had the same lowest mean values $(\mathrm{M}=2.29, \mathrm{SD}=.844)$. These items include messages that are similar to the study's cumulative descriptive results. Item 1 'The role of grammar in a language can be seen as a framework of a language, i.e. a basic system on which other aspects are built.' had the highest mean value (Mean Value $=3,08, \mathrm{SD}=.828$ ). It can be inferred from these findings that the mean values of the responses to the questionnaire's items range between 2 to 3 .

Based on the evidence gathered over the results of this study, it has been concluded that the participants maintain a positive attitude concerning the importance of grammar in EFL/ESL teaching instructions. They were unanimously in agreement regarding its importance and reiterated that students with good grammatical skills acquired the target language with greater proficiency. Training programs were found to boost the teachers' grammar teaching skills and confidence levels, who believed that they had received adequate training to teach formal grammar.

The participants of the study agreed that a proper understanding of grammatical structures played a key role in helping students master an FL/L2, especially when language learning opportunities were restricted to the classroom 
environment. Simulating scenarios where grammatical rules had to be applied in real-time was preferred over a tedious analysis of grammar structures and points. Teachers believed that communicative abilities improved faster when students practised and studied the target language's grammatical rules. Over $304 \mathrm{EFL}$ teachers who participated in this study acknowledged that grammar learning was crucial for greater FL/L2 proficiency. The views held by the teachers shaped their teaching attitude and classroom practices. A majority of them preferred teaching grammar via explicit formal instructions; however, many teachers also utilized deduction strategies in their classrooms. Both written and spoken class activities were utilised for helping students progress in their EFL studies.

Participants were also found to favour error correction strategies. They believed in correcting grammatical mistakes in class even when such mistakes did not affect the overall comprehensibility of what was being spoken. Similarly, teachers preferred to correct grammar mistakes in their students' writing and speaking instead of letting it go for the sake of enhancing their students' fluency and confidence levels. L2 teachers should look at their learners' errors positively for the reason that their errors might be a big indicator of their language competence at a certain point of time and as a mandatory aspect of learning. However, participants agreed that they did not believe in correcting mistakes immediately by interrupting their students. They preferred to let them speak their piece before pointing out the errors in their speech.

The results revealed that explicit grammar teaching strategies were preferred by most teachers, where rules were laid out formally to the students. However, they did employ implicit teaching strategies wherever possible. Additionally, many teachers believed that whether to employ deductive or inductive teaching methods was primarily dependent on the grammar points that were being taught. However, no method was upheld as a panacea by the teachers, who believed that the difficulty level of the grammatical rule under study should not influence teaching methods. Interestingly, all participants refuted a statement that said that grammar should only be explained as and when they appear in communication or materials (context-based teaching).

The responses of the participants revealed that inductive grammar teaching methods were preferred. Explicit grammar exercises were used to further this objective. The repeated practice was thought to help learners attain fluency, leading to wider adoption of repetitive grammar drills. The study offers empirical evidence to support existing literature that claims EFL teachers to prefer direct grammar teaching methods.

It must be remembered that there is no ultimate solution that can cure all ailments in ELT. Due to their context-specific nature, all methods are useful when deployed in the right circumstances. Similarly, Canh and Barnard (2009) conducted a study involving 29 Vietnamese ELT teachers and arrived at similar results; grammar was identified to be a vital part of ELT classes. Another study involved 55 Dominican ELT teachers who were found to prefer traditional grammar teaching practices (Diaz et, al. 2019).

However, several studies claim that grammar teaching has detrimental effects on language learning (Borg \& Burn, 2008; Lin, 2016; Onalan, 2018B; Sato \& Oyanedel, 2019). Sato and Oyanedel (2019) concluded that grammar-oriented teaching strategies were not useful and claimed that grammar's role was only to aid communicative language teaching. Consistent with these findings, Borg and Burn (2008) concluded in a study involving 55 ELT teaching that grammar had to be integrated with skill-work instead of being taught in isolation. Lin (2016) also arrived at similar results in a study involving 52 ELT teachers.

4.2 Do English Teachers' Perceptions Towards the Role of Teaching Grammar in EFL/ESL Classrooms Diverge Noticeably in Terms of Gender, Country, Seniority, Background Education, and Age?

\subsubsection{Teachers' Perceptions and Gender}

Over 169 females and 135 males participated in the study, with mean values at 103.67 and 103.37. SD was calculated at 13.69 and 16.14 respectively (Table 3).

Table 3. Descriptive Statistics of Gender

\begin{tabular}{lcccc}
\hline Gender & $\mathrm{N}$ & Mean & Std. Deviation & Std. Error \\
Male & 135 & 103.37 & 16.14 & 1.38 \\
Female & 169 & 103.67 & 13.69 & 1.05 \\
\hline
\end{tabular}

Independent samples t-test revealed that the perceptions held by female and male participants regarding the role of grammar in ELT classes did not vary significantly $(\mathrm{t}=0.859, \mathrm{p}>0.5)$. The $\mathrm{t}$-test value stood higher than the cut-off 
point at 0.05 (Table 4).

Table 4. Independent Samples T-test Results of Grammar Perceptions Regarding Gender

\begin{tabular}{|c|c|c|c|c|}
\hline & \multicolumn{2}{|c|}{ Levene's Test for Equality of Variances } & \multicolumn{2}{|c|}{ t-test for Equality of Means } \\
\hline & $\mathrm{F}$ & Sig. & df. & t-test for \\
\hline & & $\mathrm{t}$ & & Equality of \\
\hline & & & & Means \\
\hline \multirow[t]{2}{*}{ Equal variances assumed } & .892 & .346 & 302 & .859 \\
\hline & & -.178 & & \\
\hline \multirow[t]{2}{*}{ Equal variances not assumed } & & & 262.977 & .862 \\
\hline & & -.174 & & \\
\hline
\end{tabular}

Table 3 proves and supports the findings in Table 4. There are no significant descriptive variations between participants from the two genders, proving that both genders hold similar perceptions. Although some might observe a link between gender and language teaching styles, this study proves otherwise as far as grammar is concerned. Table 3 reveals that both genders have similar opinions on the importance of grammar. Sharabyan (2011) performed a mixed-method study in Iran to investigate ELT male teachers' grammar perceptions in classroom situations and arrived at the same conclusion.

\subsubsection{Teachers' Perceptions and Country}

All countries have different priorities in their education policy, which has affected the country's ELT practices significantly. Participants from over 22 countries were questioned about their perceptions regarding grammar teaching in ELT, which has been presented in Table 5.

Table 5. Anova Table on Teachers' Country of Origin and Grammar Perceptions

\begin{tabular}{lccccc}
\hline & Sum of Squares & df & Mean & F & Sig. \\
& & & Square & & \\
Between Groups & 11692.662 & 21 & 556.793 & 2.866 & .000 \\
Within Groups & 54780.865 & 282 & 194.258 & & \\
Total & 66473.526 & 303 & & & \\
\hline
\end{tabular}

Table 5 reveals certain statistically significant differences in participants' perceptions held by different countries concerning grammar, regarding the cut-off point of the 0.05 level of significance $(p<.05)$. While some countries focus on communicative language teaching, others prefer grammar-intensive ELT classes. Since many fields have to be covered under ELT, different countries have evolved different education policies for dealing with this. For example, countries like Turkey prioritize the four Cs (communicative, critical, creative, and collaborative) over grammar, thus improving their students' innovation and learning skills. The EU has similar guidelines in place since 2000 as well, which has been specifically spelt out by the Common European Framework of Reference for Languages (Onalan, 2018B). Borg and Burns (2008), which involved 170 participants, concluded that an ELT teacher's country of origin had a tangible impact on their perceptions regarding grammar.

\subsubsection{Teachers' Perceptions and Seniority}

The link between seniority and perceptions have been analysed in this study. Perceptions are subject to frequent change due to improved methods, updated approaches, awareness conferences or seminars, and professional training programs, all of which fall under seniority. Table 6 presents ELT teachers' data regarding their perceptions of grammar after accounting for their seniority. 
Table 6. Descriptive Statistics on Seniority and ELT Teachers' Grammar Perceptions

\begin{tabular}{lcccc}
\hline Seniority range & $\mathrm{N}$ & Mean & Std. Deviation & Std. Error \\
\hline Less than 1 year & 17 & 96.5882 & 8.329 & 2.020 \\
$1-3$ & 64 & 106.109 & 17.964 & 2.245 \\
$4-6$ & 97 & 107.371 & 14.467 & 1.468 \\
$7-9$ & 68 & 102.926 & 12.212 & 1.480 \\
$10+$ & 58 & 97.051 & 13.118 & 1.722 \\
Total & 304 & 103.539 & 14.8116 & .849 \\
\hline
\end{tabular}

Surprisingly, participants in the seniority range 4-6 had the highest mean values (Mean value $=107.371, \mathrm{SD}=$ 14.467). Although related studies ( $\mathrm{Li} \& \mathrm{Walsh}, 2011$ ) claim that novice teachers disapprove of traditional grammar teaching methods, Table 7 proves otherwise. Experienced ELT teachers disapprove of grammar-intensive language teaching (Mean Value $=97.051, \mathrm{SD}=13.118$ ). It is possible that their experiences may have changed their perceptions over time. It could be that while novice ELT teachers are trained in the latest teaching practices, this must be complemented with real-life classroom experience. Seniority indicates maturity since senior teachers have had more time to test and evaluate different teaching methods (Li \& Walsh, 2011). An ANOVA test has been employed to arrive at an exact answer. Homogeneity of the variances has also been ensured (Table 7).

Table 7. Test of Homogeneity of Variances

\begin{tabular}{lc}
\hline Levene Statistic & 2.873 \\
df1 & 4 \\
df2 & 299 \\
Sig. & .023 \\
\hline
\end{tabular}

As per Table 7, the homogeneity of variance is negative. This value is supposed to be greater than 0.05 ( $\mathrm{p}>0.05)$ as per other relevant studies; however, it is 0.023 in the present study, leading the authors to employ the Tamhane test instead of the ANOVA test for measuring the link between seniority and perceptions held by ELT teachers regarding grammar (Table 8).

Table 8. Tamhane Test on Seniority and ELT Teachers' Grammar Perceptions

\begin{tabular}{lcccc}
\hline Seniority $(\mathrm{I})$ & Seniority $(\mathrm{J})$ & Mean Difference (I-J) & Std. Error & Sig. \\
Less than 1 year & $1-3$ & -9.521 & 3.020 & .025 \\
& $4-6$ & -10.782 & 2.497 & .001 \\
& $7-9$ & -6.338 & 2.504 & .149 \\
$1-3$ & $10+$ & -.463 & 2.654 & 1.000 \\
& Less than 1 year & 9.521 & 3.020 & .025 \\
$4-6$ & -1.261 & 2.683 & 1.000 \\
$4-6$ & $7-9$ & 3.182 & 2.689 & .935 \\
& $10+$ & 9.057 & 2.830 & .018 \\
& Less than 1 year & 10.782 & 2.497 & 1.000 \\
& $1-3$ & 1.261 & 2.683 & .935 \\
& $7-9$ & 4.444 & 2.085 & .018 \\
& $10+$ & 10.319 & 2.263 & .001 \\
\hline
\end{tabular}




\begin{tabular}{ccccc}
\hline $7-9$ & Less than 1 year & 6.338 & 2.504 & 1.000 \\
$1-3$ & -3.182 & 2.689 & .297 \\
$4-6$ & $-4, .444$ & 2.085 & .000 \\
$10+$ & 5.874 & 2.271 & .149 \\
$10+$ & .463 & 2.654 & 1.000 \\
& Less than 1 year & -9.057 & 2.830 & .018 \\
$1-3$ & -10.319 & 2.263 & .000 \\
$4-6$ & -5.874 & 2.271 & .104 \\
\hline
\end{tabular}

Table 8 proves a tangible link between an ELT teacher's seniority (years of experience) and their perceptions regarding the importance of grammar. Every classroom activity affects their perceptions to a certain extent. While novice teachers prefer grammar-oriented ELT strategies, they eventually move on to context-based teaching strategies with increasing experience and maturity. Canh and Barnard (2009) concluded that experience affected the perceptions and belief systems of ELT teachers. Li (2017) proved a link between cognition and experience that lent credibility to this theory. However, Basturkmen (2012) concluded that experiences did not always have the final word in teaching strategies. Some classroom activities were found to be independent of the seniority factor.

\subsubsection{Teachers' Perceptions and Background Education}

There is an important link between one's background or academic education and their perceptions, approaches, and teaching methods since teaching strategies are highly based on the type of education they had access to. The same can be seen in ELT teachers' case and their perceptions regarding grammar teaching as well. Here is a complete breakdown of the ELT teachers' background education who participated in this study (Table 9).

Table 9. Descriptive Statistics of Participant Teachers' Background Education

\begin{tabular}{lcccc}
\hline Background Education & $\mathrm{N}$ & Mean & Std. Deviation & Std. Error \\
High School & 10 & 106.800 & 16.198 & 5.122 \\
Associate Degree & 48 & 106.708 & 17.138 & 2.473 \\
Diploma Degree & 20 & 103.700 & 19.369 & 4.331 \\
Bachelor's Degree & 64 & 106.140 & 12.222 & 1.527 \\
Master Degree & 123 & 102.487 & 14.709 & 1.326 \\
Doctorate Degree & 39 & 97.769 & 11.368 & 1.820 \\
Total & 304 & 103.539 & 14.811 & .849 \\
\hline
\end{tabular}

An analysis of the data in Table 10 reveals that the mean values of teachers' perceptions regarding grammar do not deviate significantly. The highest mean values belong to High School graduates $(106.800, \mathrm{SD}=16.198)$, Associate Degree graduates (Mean Value $=106.708, \mathrm{SD}=17.138$ ), and Bachelor's Degree graduates (Mean Value $=106.140$, $\mathrm{SD}=12.222$ ), the lowest mean value was yielded from Doctorate Degree graduates (Mean Value $=97.769, \mathrm{SD}=$ 11.368). Table 11 supports Table 10 in terms of the homogeneity of variances (see Table 10).

Table 10. Test of Homogeneity of Variances of Participants' Background Education

\begin{tabular}{lc}
\hline Levene Statistic & 1.214 \\
df1 & 5 \\
df2 & 298 \\
Sig. & .302 \\
\hline
\end{tabular}

Table 11 proves a balance in terms of the participants' breakdown of background education $(\mathrm{p}>0.05)$. Due to this 
result, the Anova test has been employed for a detailed examination of the link between background education and the perceptions held by ELT teachers regarding grammar (Table 11).

Table 11. Anova Results of ELT Teachers' Grammar Perceptions Regarding Background Education

\begin{tabular}{lccccc}
\hline & Sum of Squares & df & Mean Square & F & Sig. \\
Between Groups & 2456.420 & 5 & 491.284 & 2.287 & .046 \\
Within Groups & 64017.106 & 298 & 214.823 & & \\
Total & 66473.526 & 303 & & & \\
\hline
\end{tabular}

The results gained from the ANOVA test, displayed in Table 11, prove that there is no substantial variance among different groups $(\mathrm{p}<0.05)$, meaning that there is no link between a teacher's background education and their perceptions regarding grammar teaching. While some claim that such a link does exist, other studies (Canh \& Barnard, 2009; Afshar \& Bagherieh, 2013) do not agree with such claims. Li (2017) stated that humans are naturally open to changes and improvements, which is equally applicable to teachers.

Given that language is constantly evolving, ELT teachers are more open to changes and improved teaching methods. ELT teachers need to upgrade their skills and teaching styles to match with the current generation of students. A successful method may become out-dated with time, thus requiring teachers to develop new teaching techniques. Adaptability is the name of the game here.

Tilma (2000) supports the general opinion voiced by numerous basic education studies: teaching is a cognitive activity linked to their earlier educational activities. The beliefs held by teachers greatly affect their teaching strategies, especially their grammar instruction methods. Every century has seen a massive shift in the existing paradigm - while grammar-translation teaching methods used to be popular in the past, it is now being used in conjunction with different methods to enable communicative teaching, which is also known as the emergentist approach. While reading, listening, writing, and communication were prioritised earlier, scholars today emphasise improving one's skills in these four spheres: critical thinking, creativity, collaboration, and communication (Eaton, 2010; Fandino, 2013). The four Cs seek to improve grammatical skills and recognise their importance.

Another important thing worth remembering is that the teachers' educational background is influenced to a great extent by their country's educational policy. While some countries prioritise grammar learning, others disapprove of this view, as can be observed from the response to Question 2 in this study. Therefore, the results observed in Table 11 are unsurprising outcome. ELT programs need to be redesigned over time to be effective.

4.2.5 Teachers' Perceptions and Age

Although age is typically associated with seniority, there is a specific context to it. Old teachers should not be considered experienced if they have not regularly taught in real classrooms. Similarly, young teachers should not be considered novices without going through their previous experience in the CV. Experience can be independent of age. It all comes down to teachers' practices, strategies, and teaching methods in their classrooms. Since age and seniority are often interchangeable, the relationship between age and ELT has been a subject of great interest. Some scholars believe that the younger generation is generally more enthusiastic about upgrading their practices to the latest teaching techniques, regardless of the required effort. However, others believe that younger teachers are not efficient in picking the right practices since they have theoretical wisdom, which does not always translate effectively in real-life situations. This study analysed teachers' perceptions regarding grammar, which has been presented in Table 12.

Table 12. Descriptive Statistics of ELT Teachers' Perceptions of Grammar Regarding Age

\begin{tabular}{lllll}
\hline Age range & N & Mean & Std. Deviation & Std. Error \\
$25-29$ & 80 & 99.950 & 11.058 & 1.236 \\
$30-34$ & 92 & 107.282 & 15.439 & 1.609 \\
$35-39$ & 65 & 104.707 & 14.203 & 1.761 \\
$40-44$ & 39 & 102.717 & 19.310 & 3.092 \\
\hline
\end{tabular}




\begin{tabular}{lllll}
$45-49$ & 11 & 103.000 & 10.188 & 3.071 \\
$50-54$ & 8 & 102.000 & 20.605 & 7.285 \\
$55-59$ & 6 & 96.000 & 11.349 & 4.633 \\
$60-64$ & 2 & 95.000 & 4.242 & 3.000 \\
$65-69$ & 1 & 83.000 & $\cdot$ & $\cdot$ \\
Total & 304 & 103.539 & 14.811 & .849 \\
\hline
\end{tabular}

The number of participants is greatest in the age groups of (respectively) $30-34(\mathrm{~N}=92, \mathrm{M}=107.282, \mathrm{SD}=$ 15.439), $25-29(\mathrm{~N}=80, \mathrm{M}=99.950, \mathrm{SD}=11.058)$ and $35-39(\mathrm{~N}=65, \mathrm{M}=104.707, \mathrm{SD}=14.203)$. The age groups of $65-69(\mathrm{~N}=1, \mathrm{M}=83, \mathrm{SD}=-), 60-64(\mathrm{~N}=2, \mathrm{M}=95, \mathrm{SD}=4.242)$, and $55-59(\mathrm{~N}=6, \mathrm{M}=96, \mathrm{SD}=$ 11.349) had the lowest number of participants. Table 13 demonstrates that though the age ranges of the participants are astatic, mean values of the age ranges are close to each other; there are not any statistically significant gaps between them, considering the number of participants. For ANOVA, groups with only one case were ignored while conducting the test of homogeneity of variance. In order to examine the link between perceptions held by ELT teachers regarding grammar and their age, homogeneity of variances was ensured $(p>.05)$.

Table 13. Anova Results of ELT Teachers' Grammar Perceptions Regarding Age

\begin{tabular}{lccccc}
\hline & Sum of Squares & df & Mean Square & F & Sig. \\
\hline Between Groups & 3365,731 & 8 & 420.716 & 1.967 & .050 \\
Within Groups & 63107,796 & 295 & 213,925 & & \\
Total & 66473,526 & 303 & & & \\
\hline
\end{tabular}

According to Table 13, the cut-off point needs to be higher than 0.05 ( $\mathrm{p}>.05)$ in order for there to be any statistically significant differences between the groups. However, in the present study, it is equal to $.05(\mathrm{p}=0.05)$. This one-way ANOVA result implies that teachers' perceptions of grammar do not vary considerably as far as age is concerned.

Due to the prominent role played by teachers' beliefs in their grammar teaching strategies, numerous studies have analysed this aspect in detail from different perspectives like gender, background education, seniority, age, etc. However, they only examined the importance of grammar in ELT programs from a single perspective, unlike the current study, which approached the issue from numerous perspectives to achieve a generalised conclusion. The results are consistent with the findings of Borg and Burns (2008), which involved 176 participants from 18 countries, where it was concluded that age did not affect the perceptions of ELT teachers regarding grammar.

\section{Pedagogical Implications and Recommendations}

In line with the previous studies conducted in the same area of research as well as the major findings of the current study, it is recommended that incorporating interactive sessions and activities into the lessons is a great way to boost productivity. Teachers can use communicative activities through hands-on practices depending on the movement of 'learning by doing'. Under these frame demonstrations, story-telling, problem-solving, games, picture descriptions, and analytical activities are favourable options to present grammatical structures saliently (Onalan, 2018A; Diaz et al., 2019).

Teaching grammar in a contextual manner requires learners to make connections between different grammar rules and important elements such as the meaning of the texts, wider contextual factors like purpose, subject, audience, and genre; potential motivations for decisions like language choices; and a reader's responses and feelings while reading a text. That is why appropriate context should be chosen, which means that context and the emphasized grammatical subjects should be parallel. 'Appropriate context' here means that grammar teaching needs to be integrated into other crucial aspects of the academic curriculum, like analytical reading and creative writing, instead of treating it as an isolated activity. If circumstances leave no choice but to strip an item of its context for drawing better attention, it is important to re-contextualise it at the earliest. Similarly, grammatical forms must be taught with a clear understanding of their meanings and applications. The meaning wished to be conveyed by the writer or speaker will always dictate their choice of grammatical forms. Such these activities were likewise highly suggested by some recent studies (Iqbal et al., 2017; Canh \& Barnard 2009; Borg \& Burns, 2008). 
Learning grammar in isolation is extremely inefficient since students become unaware of grammatical mistakes in their own writing. Diagramming sentences do not have any meaningful contribution to the learning process (Al-Mekhlafi \& Nagaratnam, 2011; Toprak, 2019). As this in line with the findings of the study, it is recommended that extensive writing and reading will always play an important role in grammar teaching strategies. This involves teachers reading the texts aloud to their students or making them proofread regardless of their age and academic levels. When students see and hear the proper form of the text or edit and revise the text, they learn how to integrate the rules into active language practices. To derive maximum advantage out of this, teachers must provide ample opportunities for their students to write and read in their classroom. While doing this, teachers are recommended to attract students' attention in the direction of being creative and critical, which is prioritized by four basic skills.

As a final point and in light of the findings obtained, this study concludes that excluding grammar teaching from language education is a frozen myth: since languages are formed around their rules. And it has been recognized to play an important role in enhancing the communicative abilities of language learners, thus causing it to be highly prioritized by teachers worldwide. It is a tool that can help learners comprehend written or oral discourse and should not be restricted to only being applied at a rudimentary level. Grammar should be adopted as a by-product of the language education process, not the end-product. This implies that pulling out grammar from language education cannot be even a matter of discussion. Grammar teaching instruction for EFL and ESL learners should help them internalize different patterns and rules, which can be then applied during actual communication. When presented with the right context, grammar can elevate social functions and meaning properly. Both deductive and inductive grammar teaching methods must be used with the right balance after due consideration of the learners' educational level, objectives, needs, learning styles, error correction feedback, salience and frequency of the input, and the requirement of different meaningful, authentic, and communicative tasks and activities.

\section{Conclusion}

After due analysis of the responses of 304 English teachers from 22 countries, this study concluded that ELT teachers maintain highly positive perceptions regarding the importance of grammar teaching in ELT. Students with excellent grammatical skills acquire greater proficiency in the target language. Immediate correction of grammatical mistakes was detrimental to their self-confidence and only served as an unnecessary interruption to their language learning process. Inductive techniques and implicit teaching approaches were deemed preferable. While age, gender, and educational background were found to exercise no significant effect on the participants' perspectives, seniority and country of origin were observed to have a marked effect.

Additional empirical research needs to be done to understand the extent to which grammar teaching perceptions held by teachers influence their teaching strategies. Doing so can provide policymakers, teachers, educators, and curriculum designers with better constructive insights, which promote contemplative thinking and teacher development through structuring in- and pre-service teaching programs. Other variables like language proficiency and motivation should also be explored to discover the effect they have on grammar learning strategies.

\section{References}

Afshar, H. S., \& Bagherieh, M. (2014). An evaluation of grammar and vocabulary consciousness-raising activities in current ELT materials. Procedia-Social and Behavioural Sciences, 136, 109-113. https://doi.org/10.1016/j.sbspro.2014.05.298

Al-Mekhlafi, A. M., \& Nagaratnam, R. P. (2011). Difficulties in teaching and learning grammar in an EFL context. International Journal of Instruction, 4(2), 69-92.

Alsied, S. M., Ibrhaim, W. N., \& Pathan, M. M. (2018). The use of grammar learning strategies by Libyan EFL Learners at Sebha University. ASIAN TEFL: Journal of Language Teaching and Applied Linguistics, 3(1), 37-51. https://doi.org/10.21462/asiantefl.v1i1.40

Barnard, R., \& Scampton, D. (2008). Teaching grammar: A survey of EAP teachers in New Zealand. New Zealand Studies in Applied Linguistics, 14(2), 59-82.

Basturkmen, H. (2012). Review of research into the correspondence between language teachers' stated beliefs and practices. System, 40(2), 282-295. https://doi.org/10.1016/j.system.2012.05.001

Bell, H. (2016). Teacher knowledge and beliefs about grammar: a case study of an English primary school. English in Education, 50(2), 148-163. https://doi.org/10.1111/eie.12100

Bernat, E., \& Gvozdenko, I. (2005). Beliefs about language learning: current knowledge, pedagogical implications, and new research directions. The Electronic Journal for English as a Second Language, 9(1), 1-21. 
Borg, S., \& Burns, A. (2008). Integrating grammar in adult TESOL classrooms. Applied Linguistics, 29(3), 456-482. https://doi.org/10.1093/applin/amn020

Brown, J. D., \& Rodgers, T. S. (2002). Doing second language research. Oxford, England: Oxford University Press.

Burchfield, R. (2006). The English Language. London: The Folio Society.

Canh, L. V., \& Barnard, R. (2009). Curricular innovation behind closed classroom doors: A Vietnamese case study. Prospect : an Australian journal of TESOL, 24(2), 20-33. http://hdl.handle.net/1959.14/330902

Canh, L. V., \& Barnard, R. (2009). Teaching grammar: A survey of teachers' attitudes in Vietnam. The Journal of Asia TEFL, 6(3), 245-273.

Creswell, J. W. (2002). Educational research: Planning, conducting, and evaluating quantitative. Upper Saddle River, NJ: Prentice Hall.

Crystal, D. (2003). English as a global language. Cambridge: Cambridge University Press. https://doi.org/10.1017/CBO9780511486999

Diaz, L. A., Martinez, J., Jiménez, D., Perez, E., \& Mateo, V. (2019). How we teach grammar: an exploratory study on how Dominican teachers deal with grammar teaching. MEXTESOL Journal, 43(4), 1-9.

Duddleston, R., \& Pullum, G. K. (2003). The Cambridge grammar of the English language. Cambridge: Cambridge University Press. https://doi.org/10.1017/9781316423530

Due, C., Riggs, D. W., \& Mandara, M. (2015). Educators' experiences of working in intensive English language programs: The strengths and challenges of specialized English language classrooms for students with migrant and refugee backgrounds. Australian Journal of Education, 59(2), 1-13. https://doi.org/10.1177/0004944115587365

Eaton, S. E. (2010). Global trends in language learning in the twenty-first century. Calgary: Onate Press

Ellis, R. (2006). Current Issues in the Teaching of Grammar: An SLA Perspective. TESOL Quarterly, 40(1), 83-107. https://doi.org/10.2307/40264512

Fandiño, P. Y. (2013). 21st century skills and the English foreign language classroom: A call for more awareness in Colombia. Gist- Education and Learning Research Journal, 7, 190-208.

Farrell, T. S., \& Kun, S. T. K. (2007). Language policy, language teachers' beliefs, and classroom practices. Applied Linguistics, 29(3), 381-403. https://doi.org/10.1093/applin/amm050

Hurn, B. J., \& Tomalin, B. (2013). The international use of English. In: Cross-Cultural Communication. Palgrave Macmillan, London. https://doi.org/10.1057/9780230391147

Iqbal, J, M., Akbar, M., \& Ahmed, M. (2017). Problems in teaching grammar to English learners at secondary level. Asian Innovative Journal of Social Sciences \& Humanities, 1(1), 55-69.

Kumar, R. (2011) Research Methodology: A Step-by-Step Guide for Beginners (3rd ed.). Sage, New Delhi.

Larsen-Freeman, D. (2001). Grammar. In R. Carter \& D. Nunan (Eds.), The Cambridge guide to teaching English to speakers of other languages (pp. 34-41). New York: Cambridge University Press. https://doi.org/10.1017/CBO9780511667206.006

Li, L. (2017). Social interaction and teacher cognition. Edinburgh: Edinburgh University Press.

Li, L., \& Walsh, S. (2011). 'Seeing is believing': looking at EFL teachers' beliefs through classroom interaction. Classroom discourse, 2(1), 39-57. https://doi.org/10.1080/19463014.2011.562657

Lin, M. H. (2016). Effects of corpus-aided language learning in the EFL grammar classroom: A case study of students' learning attitudes and teachers' perceptions in Taiwan. TESOL Quarterly, 50(4), 871-893. https://doi.org/10.1002/tesq.250

Mair, C. (2005). Recent Advances in contrastive linguistics and language typology: The spin-off for language teachers. In J. David., C. Allerton., Tschichold \& J. Wieser (Eds.), Linguistics, language teaching and language learning (pp. 21-39). Basel: Schwabe.

McGregor, W. (2009). Linguistics: An Introduction. London \& New York: Continuum

McWhorter, J. (2012). What Language Is: And What It Isn't and What It Could Be. Los Angeles: Gotham.

Morenberg, M. (1991). Doing grammar. Oxford: Oxford University Press. 
Onalan, O. (2018A). EFL teachers' perceptions about teaching grammar: a comparative study between novice and experienced teachers. Science Journal of Turkish Military Academy, 28(1), 109-125.

Önalan, O. (2018B). Non-native English teachers' beliefs on grammar instruction. English Language Teaching, 11(5), 1-13. https://doi.org/10.5539/elt.v11n5p1

Pagcaliwagan, S. B. (2016). Cooperative learning strategy: Effects on students' performance in grammar. European Journal of English Language, Linguistics and Literature, 3(1), 40-49.

Pandian, A., Tan, S., \& Ismail, A. (2011). Teaching and learning language: Current trends and practices. Malaysia: Penerbit Universiti Sains Malaysia.

Procter, P. (1978). Longman dictionary of contemporary English. Harlow -England: Longman.

Pudin, C. S. J. (2017). Exploring a flipped learning approach in teaching grammar for ESL students. Indonesian Journal of English Language Teaching and Applied Linguistics, 2(1), 51-64. https://doi.org/10.21093/ijeltal.v2i1.47

Rao, S. P. (2019). The role of English as a global language. Research Journal of English, 4(1), 65-79.

Richards, J. C., \& Rodgers, T. S. (2016). Approaches and methods in language teaching. Cambridge, UK: Cambridge University Press.

Sato, M., \& Oyanedel, J. C. (2019). "I think that is a better way to teach but...”: EFL teachers' conflicting beliefs about grammar teaching. System, 84, 110-122. https://doi.org/10.1016/j.system.2019.06.005

Sharabyan, S. K. (2011). Experienced and very experienced Iranian English language teachers: Beliefs about grammar instruction. Procedia-Social and Behavioral Sciences, 30, 1081-1085. https://doi.org/10.1016/j.sbspro.2011.10.211

Tillema, H. H. (2000). Belief change towards self-directed learning in student teachers: Immersion in practice or reflection on action. Teaching and Teacher Education, 16(5-6), 575-591. https://doi.org/10.1016/S0742-051X(00)00016-0

Toprak, T. E. (2019). “Teaching grammar is not my main responsibility": Exploring EFL teachers' beliefs about grammar teaching. International Online Journal of Education and Teaching, 6(1), 205-221.

Yusof, F. K. (2018). Challenges of teaching grammar at tertiary level: learning from English lecturers' insights. UiTMT E-Academia Journal, 7(1), 149-158.

Zheng, H. (2013). Teachers' beliefs and practices: A dynamic and complex relationship. Asia-Pacific Journal of Teacher Education, 41(3), 331-343. https://doi.org/10.1080/1359866X.2013.809051

\section{Copyrights}

Copyright for this article is retained by the author(s), with first publication rights granted to the journal.

This is an open-access article distributed under the terms and conditions of the Creative Commons Attribution license (http://creativecommons.org/licenses/by/4.0/). 